\title{
DIGNIDADE DA MULHER E EPISIOTOMIA: CONTRIBUTOS DE UMA ANÁLISE PAUTADA NAS CAPACIDADES CENTRAIS DE MARTHA NUSSBAUM
}

\author{
Roberto Henrique Pôrto Nogueira ${ }^{1}$ \\ Karine Lemos Gomes Ribeiro ${ }^{2}$
}

\section{RESUMO:}

O presente ensaio pretende aferir as circunstâncias nas quais a episiotomia pode ser considerada ofensiva à dignidade das mulheres gestantes. $\mathrm{O}$ marco para a reflexão jurídicodogmática e teórico-descritiva é a ideia de que a dignidade pode ser entendida como sendo delineada por parâmetros mínimos para uma vida digna a partir da Teoria das Capacidades, de Martha Nussbaum. A relevância do estudo é evidenciada por coadunar com lutas e reivindicações feministas. Conclui-se que a dignidade humana tende a ser violada quando da realização de procedimentos não autorizados, desfundamentados cientificamente e pautados em interesses pragmáticos alheios à subjetividade da mulher parturiente.

Palavras-chave: Dignidade da mulher; Episiotomia; Capacidades centrais; Novos direitos; Desenvolvimento humano.

\section{WOMEN'S DIGNITY AND EPISIOTOMY: CONTRIBUTIONS OF AN ANALYSIS BASED ON THE CENTRAL CAPACITIES OF MARTHA NUSSBAUM}

\begin{abstract}
:
This paper aims to assess the circumstances in which episiotomy might be considered offensive to the dignity of pregnant women. The parameter for the legal-dogmatic and theoretical-descriptive reflection is the idea that dignity can be understood as being outlined by minimum content for a dignified life based on the Capability Approach, by Martha Nussbaum. The relevance of the study is evidenced by the fact that it fits with feminist struggles and claims. It is concluded that human dignity tends to be violated when performing unauthorized procedures, scientifically defunded and based on pragmatic interests unrelated to the subjectivity of parturient women.
\end{abstract}

Keywords: Women's dignity; Episiotomy; Central capabilities; New rights; Human development.

\section{INTRODUÇÃO}

\footnotetext{
${ }^{1}$ Doutor e Mestre em Direito Privado (PUC Minas). Professor de Graduação/Mestrado em Direito (UFOP). Pesquisador em 'Novos Direitos Privados' e 'Centro de Estudos em Biodireito'. AUXÍlLIO PESQUISADOR UFOP 2017-2018-2019. Endereço: Universidade Federal de Ouro Preto. Campus Morro do Cruzeiro, S/N, Morro do Cruzeiro, Ouro Preto - MG, 35400-000. E-mail: roberto.nogueira@ ufop.edu.br

${ }^{2}$ Mestranda em Novos Direitos, Novos Sujeitos, pela Universidade Federal de Ouro Preto. Pesquisadora em 'Novos Direitos Privados' e 'Centro de Estudos em Biodireito'. Advogada. Endereço: Universidade Federal de Ouro Preto. Campus Morro do Cruzeiro, S/N, Morro do Cruzeiro, Ouro Preto - MG, 35400-000. E-mail: karinelg.ribeiro@gmail.com
} 
O presente ensaio pretende aferir as circunstâncias nas quais a episiotomia procedimento cirúrgico utilizado no momento do parto - pode ser considerado ofensivo à dignidade das mulheres gestantes.

A episiotomia é uma terminação de origem grega, que significa episio: púbis; e tomia: corte. Portanto, consiste em um corte cirúrgico na região do períneo das mulheres parturientes, que pode se firmar em fundamentos diversos.

Seus objetivos podem variar, assim como são questionáveis as pessoas admitidas como interessados e interessadas em seu acontecimento.

O marco para a reflexão jurídico-dogmática de cunho teórico é a ideia de que a dignidade pode ser entendida como sendo delineada por parâmetros mínimos para uma vida digna a partir da Teoria das Capacidades, de Martha Nussbaum (2017).

A investigação que se propõe é interdisciplinar, na medida em que visa a coordenar as ciências jurídicas e médicas que abordam a temática. A pesquisa é, ainda, jurídicodescritiva, valendo-se de dados secundários para o fim que se propõe.

Logo, a relevância do estudo é evidente, na medida em que intui reafirmar o respeito à dignidade da mulher, o que em muito se coaduna com as lutas e reivindicações feministas pela igualdade de respeito e o fim de imposições sexistas, que resvalam em violência físicas e simbólicas no campo da obstetrícia contra as mulheres. Afinal, como se demonstra a seguir, a episiotomia é cirurgia realizada no corpo de uma mulher saudável, muitas vezes sem o seu consentimento.

Dessa forma, ocupa-se de apresentar a episiotomia e as circunstâncias nas quais o procedimento é realizado no Brasil.

Então, descortina-se o marco teórico adotado para a elucidação de uma ideia de dignidade definida pela postura político-ideológica firmada para a finalidade analítica proposta. Logo, com tal escorço, parece viável, hipotético-dedutivamente, averiguar se, conforme os marcadores adotados, é revelada violência contra a dignidade da mulher parturiente.

A hipótese, portanto, é a de que a episiotomia é procedimento obstétrico que pode violar a dignidade das mulheres parturientes, posto que pode comprometer algumas capacidades centrais ligadas à sua saúde, integridade física e afiliação.

\section{O DIREITO PRIVADO E O PERSONALISMO ÉTICO}


Uma compreensão teleológica possível, a partir da análise conjuntural dogmática da Constituição brasileira (BRASIL, 1988), é a de que a igual dignidade (no latim dignitas, "merecimento", "valor", "nobreza") é uma das finalidades centrais do Direito Privado, ao lado do igual reconhecimento. (DRESCH, 2013, p. 155). Isso porque a dignidade está imbricada no igual respeito a todos os seres humanos, conferindo um status de nobreza às pessoas no ordenamento jurídico, independentemente de suas identidades ou singularidades.

Segundo Rafael de Freitas Valle Dresch, "a igual dignidade sustenta-se na noção de que, como seres humanos, todos somos igualmente dignos de respeito" (2013, p. 139). Por conseguinte, a dignidade e o respeito são duas faces de uma mesma moeda. Segundo José de Oliveira Ascensão (2013, p. 13), “[...] a pessoa, na sua substância, é a âncora da fundamentação da ordem jurídica. Dá a legitimação do Direito: que na incidência direta sobre as pessoas em si, que na incidência sobre o enquadramento social que lhes cabe.”

Não obstante, a Constituição da República (BRASIL, 1988) é elo, fundamental para a concretização dessa dignidade da pessoa humana nas relações entre particulares (DRESCH, 2013, p. 151). Nesse sentido, dignidade é tida como fundamento da própria República (art. $1^{\text {a }}$, III, da Constituição), e, ainda, manifesta-se em dispositivos que definem os direitos fundamentais e os princípios correlatos, que consubstanciam ou preenchem parte significativa do conteúdo da aludida dignidade da pessoa humana. Dentre eles, para os fins do presente trabalho, destacam-se a tutela à integridade física em sentido amplo ${ }^{3}$ e o direito à saúde ${ }^{4}$.

Nesse diapasão, Maria Celina Bodin de Moraes (2003, p. 83, apud SOUZA, 2009, p. 258) destaca a importância do princípio em causa. Segundo a autora, “[...] a Constituição consagrou o princípio e, considerando a sua eminência, proclamou-o entre os princípios fundamentais, atribuindo-lhe o valor supremo de alicerce da ordem jurídica democrática". (MORAES, 2003, p. 83, apud SOUZA, 2009, p. 258).

\footnotetext{
3 “Art. $5^{\circ}$ Todos são iguais perante a lei, sem distinção de qualquer natureza, garantindo-se aos brasileiros e aos estrangeiros residentes no País a inviolabilidade do direito à vida, à liberdade, à igualdade, à segurança e à propriedade, nos termos seguintes:

[...]

XLIX - é assegurado aos presos o respeito à integridade física e moral.” (BRASIL, 1988).

4 “Art. 196. A saúde é direito de todos e dever do Estado, garantido mediante políticas sociais e econômicas que visem à redução do risco de doença e de outros agravos e ao acesso universal e igualitário às ações e serviços para sua promoção, proteção e recuperação.” (BRASIL, 1988).
} 
Independente dos debates sobre o status de metaprincípio da dignidade, e embora a dignidade da pessoa humana seja, a priori, inviolável, é certo que seu caráter contrafático há de oferecer resistência a práticas que fragilizam essa perspectiva protetiva da pessoa.

Deve-se destacar, ainda, que alguns grupos tendem a depender, em maior medida, da proteção esboçada pelo princípio em comento, eis que, dotados de alguma vulnerabilidade, revelam-se, na realidade dos fatos, vítimas preferenciais de práticas e contextos indignos.

Esse é o caso de pessoas identificadas com o gênero feminino, que têm lutado contra formas de opressões e pelo respeito à sua dignidade, em detrimento de possíveis hierarquias e estruturas deletérias e redutivas dos direitos. Essa realidade estende-se também às relações obstétricas, tendo em vista que se tem notícia de discussões que tangenciam violências contra pessoas do gênero feminino em hospitais públicos e particulares brasileiros.

Se, no seio de uma fundamentação normativa constitucional intrassistêmica é verossímil que qualquer forma de violência contra a dignidade das mulheres está na contramão do sistema jurídico vigente, é mister elucidar o contexto da episiotomia para, eventualmente, revelar práticas atentatórias à dignidade marcadas pela questão de gênero.

\section{O QUE É EPISIOTOMIA?}

A episiotomia é um procedimento cirúrgico obstétrico, utilizado com o intuito de ampliar a vagina para facilitar o nascimento (FRIGO et al. 2014, p. 05). É realizado no momento do parto e a justificativa mais comum para a utilização do procedimento em tela é a proteção da genitália feminina de possíveis lacerações. Consiste em um corte cirúrgico na pele e músculos na região do períneo com o auxílio de tesoura ou bisturi e necessita de sutura (FRIGO et al. 2014, p. 05).

O procedimento, que começou a ser difundido na obstetrícia por volta do século XVIII, é recorrente no momento do trabalho de parto. Isso se deve, em grande medida, ao processo de hospitalização e medicalização do nascimento, resultando no aumento da recorrência à procedimentos cirúrgicos (PRADO et al. 2017, p. 1039).

Todavia, os benefícios para a mulher quando da aplicação da episiotomia são contraditórios, posto que foi introduzido na obstetrícia sem muita evidência cientifica sobre sua efetividade (FRIGO et al. 2014, p. 05). Estudos de várias partes do mundo corroboram a 
falta de sustentação científica para a prática da episiotomia de rotina (BENTO; SANTOS, 2006, p. 556).

Quando utilizado pelo/a profissional da saúde em casos onde não há necessidade, pode trazer sequelas de curto e longo prazo ao corpo feminino, diante de sua agressividade ao períneo, como incontinência urinária e piora na função sexual, resultando em dor para a mulher (OLIVEIRA; MIQUILINI, 2005, p. 289). Relata-se que:

\begin{abstract}
A dor na episiotomia tem sido reportada como uma das causas mais comuns de morbidade materna no período pós-parto. A mulher com episiotomia tem uma experiência maior de dor e está sujeita a maior perda sanguínea, hematoma, infecção, deiscência, disfunção sexual, prolapso vaginal e fístula reto-vaginal, quando comparada com outros graus de trauma perineal. (PITANGUI et al., 2009, p. $01)$.
\end{abstract}

Diante deste cenário, a Organização Mundial da Saúde (OMS) recomenda que a taxa de recorrência pelos/as médicos/as à episiotomia seja entre 10 e 30\% dos partos, ou seja, deve ser realizada forma restrita. É indicada seletivamente para casos nos quais se julgue imprescindível para a preservação da saúde da parturiente (BRASIL, 2001, p. 115).

Do ponto de vista da saúde e dos cuidados à mulher, é suscetível de críticas a recorrência ao procedimento cirúrgico interventivo em questão nos casos em que não há risco à gestante. Não obstante, como dito, "estudos controlados demonstram que a episiotomia aumenta o risco de laceração perineal de terceiro e quarto graus, de infecção e hemorragia, sem diminuir as complicações a longo prazo de dor e incontinência urinária e fecal" (LEAL et al. 2014, p. 522- 523).

Embora tenha-se feito a recomendação pela OMS, o índice de recorrência ao procedimento ainda é alto no Brasil. Pesquisas recentes (LEAL et al. 2014, p. 521) indicam que a episiotomia é feita na porcentagem de $56 \%$ dos partos, sendo que os casos em que havia necessidade de fato correspondem a apenas 15\% deles (BENTO; SANTOS, 2006, p. 554). "Podemos concluir que o restante de episiotomias são realizadas sem qualquer indicação clínica e sustentação científica, a não ser que opiniões pessoais [...] sejam consideradas indicações." (BENTO; SANTOS, 2006, p. 554).

Dessa forma, a episiotomia pode ser considerada uma dentre as violências obstétricas contra a mulher, tendo em vista a sua utilização de forma arbitrária e injustificada no corpo da parturiente. Cumpre elucidar que o termo 'violência obstétrica' é utilizada para “descrever e agrupar diversas formas de violência (e danos) durante o cuidado obstétrico profissional. 
Inclui maus tratos físicos, psicológicos, e verbais, assim como procedimentos desnecessários e danosos [...]" (TESSER et al. 2015, p. 02), como é o caso da episiotomia de rotina.

As discussões acerca da recorrência inadequada da episiotomia resvala em diversos campos, a saber, o Direito e o movimento feminista pela saúde (KAMPF; DIAS, 2018, p. 1158). Isso porque, a participação da mulher gestante do processo de tomada de decisão pela aplicação do procedimento é limitada, ou quase desconsiderada. Dessa forma, "a episiotomia é um dos poucos procedimentos que são feitos sem consentimento da parturiente." (FRIGO et al. 2014, p. 06).

Nesse sentido,

A falta de conhecimento destas mulheres corrobora com o domínio do poder do profissional de saúde, onde predomina em muitos serviços o modelo biomédico e hegemônico do cuidado, com a exclusão da parturiente no processo decisório, anulando o protagonismo do parto. (FRIGO et al. 2014, p. 06).

Por conseguinte, a dignidade da mulher gestante é ameaçada, sendo-lhe cerceada a recusa por procedimentos cirúrgicos agressivos no parto (FRIGO et al; 2014, p. 06). Esse cenário, que deveria ser restrito apenas à casos de risco à saúde da mulher ou da criança, são, ao contrário, a regra nos partos no Brasil. (FRIGO et al. 2014, p. 06). Em geral, entende-se "a gravidez como doença e o parto como necessariamente disfuncional e perigoso e, portanto, dependente de intervenções contínuas.” (KAMPF; DIAS, 2018, p. 1157). Não obstante, médicos/as obstetras, defensores/as do parto humanizado, chegam a rechaçar a episiotomia, considerando-a verdadeira mutilação dos órgãos genitais femininos (KAMPF; DIAS, 2018, p. 1159).

Diante deste panorama, aponta-se que a episiotomia é, acima de tudo, um problema de gênero. Isso porque, ainda que sem qualquer comprovação científica favorável à sua utilização, desde o ano de1920 defendia-se o uso da episiotomia como forma de recomposição da mulher em sua condição virginal. (BENTO, SANTOS, 2006, p. 554). Pode constituir-se, dessarte, uma forma violenta de desrespeito ao corpo da parturiente.

Por oportuno, cumpre elucidar que o procedimento da episiotomia foi introduzido na obstetrícia a partir do mesmo período em que os homens puderam entrar no quarto de parir (OLIVEIRA; MILQUINI, 2005, p. 289). As maiores referências deste procedimento são Pomeroy (1918) e Joseph DeLee (1920), homens por meio dos quais a episiotomia passou a ser compreendida como procedimento de rotina. 
Não obstante, é "também reflexo da visão política voltada à saúde da mulher, que ao longo dos anos foi definida como ser da reprodução, figura feita para o lar e para os filhos, ideologia impressa nos programas políticos que definiram a saúde deste grupo." (BENTO; SANTOS, 2006, p. 552).

Por esse motivo, os movimentos feministas em saúde, desde o século XX, questionam a utilização recorrente do procedimento no Brasil. A luta contra esse tipo de procedimento durante o parto resvala, em grande medida, na luta das mulheres por seu direito à dignidade, posto que a violência obstétrica repercute na dignidade da mulher, assim como outras formas de violência de gênero.

A episiotomia de rotina tem sido considerada por vários autores como uma forma de mutilação genital, e mesmo como violência de gênero cometida pelas instituições e profissionais. O abuso de episiotomias tem sido considerado uma questão exemplar de desrespeito aos direitos humanos na área de saúde. (DINIZ, 2004, apud BENTO, SANTOS, 2006, p. 554).

Logo, cabe aludir a viabilidade de compreensão da episiotomia de rotina como um ato notadamente heteronormativo, machista e hegemônico, que objetifica o corpo e a saúde da mulher. Ana Carolina Brochado Teixeira explana que:

[...] o consentimento inaugura a passagem da concepção objetivada do corpo para uma outra, subjetivada, pois, no contexto democrático, pressupõe o respeito do direito de cada um governar livremente seu próprio corpo, o que inclui tanto a perspectiva da disposição quanto a da privacidade. Nesse sentido, só se pode permitir intervenção sobre o corpo que emane da própria vontade do seu titular; nem terceiros nem o Estado poderão intervir no corpo sem o consentimento do indivíduo, sob pena de ser este um ato ilegítimo no ordenamento jurídico. (TEIXEIRA, 2010, p. 65-66).

Nesse sentido, diante da recorrente utilização do procedimento sem embasamento científico que o justifique, denota-se que pode haver outros interesses por detrás desta intervenção cirúrgica que não a saúde e o bem-estar da mulher em trabalho de parto.

Dentre eles, pontua-se o interesse médico, tendo em vista que intervenções cirúrgicas no corpo da mulher aceleram o parto e facilitam a saída do bebê, ainda que este seja um processo fisiológico inerente ao nascimento. A objetificação da mulher parturiente é corroborada, dentre outros aspectos, pela formação médico-profissional, que incentiva as intervenções cirúrgicas no momento do parto, ao invés de entendê-lo como evento fisiológico do corpo feminino (KAMPF; DIAS, 2018, p. 1557). 
A dignidade da mulher, nestes casos, é colocada em pauta, posto que o corpo da mulher é tratado não como um fim em si mesmo e/ou protagonista do parto de seu filho, mas como meio para outros fins. (BENTO; SANTOS, 2006, p. 556).

Nesse diapasão, percebe-se que a episiotomia é um procedimento eivado de contradições, tendo em vista que o seu uso deve ser feito de forma restrita, apenas em casos de eminente necessidade. Todavia, cuida-se de uma prática costumeira nos partos no Brasil. Ao que parece, trata-se de uma prática cultural, sem justificativas científicas para que seja feita rotineiramente. As consequências para o corpo e saúde da mulher são diversas, destacando-se uma quantidade vasta de possíveis prejuízos a curto e a longo prazo, que fazem com que se questione se as dignidades das mulheres são resguardadas quando da feitura da episiotomia. Diante desse impasse, imperioso que a dignidade das mulheres seja colocada em pauta para averiguar se os prejuízos oriundos deste procedimento violam a dignidade da parturiente.

Neste contexto, cumpre apresentar o conceito de dignidade a partir da Teoria das Capacidades de Martha Nussbaum (2017) para aferir se o procedimento em causa ofende a dignidade das mulheres parturientes.

\section{DIGNIDADE DA PESSOA HUMANA E A TEORIA DAS CAPACIDADES DE MARTHA NUSSBAUM}

De acordo com Rafael de Freitas Valle Dresch (2013, p.134), a dignidade é decorrente do advento da filosofia moderna, posto que apenas com filósofos como John Locke passou-se a reconhecer uma mesma valoração para todos os seres humanos. Nesse diapasão, segundo o autor, a dignidade deixou de ser um status concedido à uma determinada classe, em prol de sua extensão como um atributo inerente à condição de ser humano. "Todos, como detentores de dignidade, merecem o mesmo respeito antes garantido somente aos nobres". (DRESCH, 2013, p. 136). Não obstante, "o pensamento moderno ganhou, nos seus pontos mais elevados, consciência do significado da pessoa e da sua real dignidade" (ASCENSÃO, 2013, p. 13).

Fato é que a dignidade humana já vinha sendo discutida no campo da filosofia desde Kant (ASCENSÃO, 2013, p. 05), motivo pelo qual a dignidade é, inicialmente, um conceito 
filosófico, importado para nosso ordenamento constitucional (SOUZA, 2009, p. 258). Maria Celina Bodin de Moraes aponta que:

\begin{abstract}
De acordo com Kant, no mundo social existem duas categorias de valores: o preço e a dignidade. Enquanto o preço representa um valor exterior (de mercado) e manifesta interesses particulares, a dignidade representa um valor interior (moral) e de interesse geral. As coisas têm preço; as pessoas, dignidade. O valor moral se encontra infinitamente acima do valor de mercadoria, porque, ao contrário deste, não admite ser substituído por equivalente. [...] Em consequência, a legislação elaborada pela razão prática, a vigorar no mundo social, deve levar em conta, como sua finalidade suprema, a realização do valor intrínseco da dignidade humana. (MORAES, 2003, p. 81 apud SOUZA, 2009, p. 257).
\end{abstract}

Nesse sentido, a dignidade consolida-se como princípio na Constituição da República (BRASIL, 1988), o que reflete em todo o ordenamento jurídico pátrio, devendo ser garantida a todos/as em igualdade, sendo incabível quaisquer distinções de raça, classe e orientação sexual. Por sua vez, o Código Civil, apesar de não referenciar a dignidade da pessoa humana expressamente, tem o princípio como corolário na relação entre particulares. A dignidade da pessoa humana expressa-se no Código Civil por meio, principalmente, dos direitos de personalidade (ASCENSÃO, 2013, p. 06). Nos ensinamentos de José de Oliveira Ascensão, ao tratar sobre a dignidade, preceitua-se que:

[...] é claro que esses direitos só se compreendem como direitos da pessoa. Mas, o ramo do Direito que está em condições de os estudar com maior pureza é o Direito Civil. [...] Só o Direito Civil pode atender à pessoa em si, sem desvios derivados de preocupações diversas.

[...]

No Direito Civil, e como que insensivelmente, foi-se difundindo a referência à pessoa, sobretudo através da fórmula consagrada da 'eminente dignidade da pessoa humana'; e a essa fórmula se foi buscar a função de fundamento da ordem jurídica. Com uma amplitude tal que as soluções mais díspares, e até as contraditórias entre si, encontraram igualmente o seu suporte nessa referência autossuficiente. (ASCENSÃO, 2013, P. 6-7).

Dessa forma, o escólio de João Maurício Penna Lamounier (2009, p. 138) esclarece que a dignidade da pessoa humana consiste em "[...] norma de aplicação imediata, por traduzir direito fundamental, não sendo, pois, norma de conteúdo meramente programático.”

Sendo uma característica inerente à condição de ser humano, todos/as devem ser paritariamente respeitados/as, sob pena de violação à dignidade do/a outro/a. Todavia, ressalte-se que, embora a igual dignidade seja inerente a todos/as, disso não decorre que todos/as devam partilhar das mesmas concepções de vida boa. Todas as singularidades e 
individualidades devem ser respeitadas, a fim de preservar a pluralidade de formas de bem viver. (DRESCH, 2013, p. 146).

Ao tratar a dignidade, Martha Nussbaum enfatiza que as pessoas devem ser merecedoras de igual respeito (NUSSBAUM, 2017, p. 51). Isso implica que todas e todos merecem igual tratamento e respeito por parte das leis e das instituições. "Se as pessoas são consideradas em sua qualidade de cidadãos e cidadãs, todas elas têm iguais direitos." (NUSSBAUM, 2017, p. 51, tradução nossa ${ }^{5}$ ). Sendo assim, a dignidade é algo inerente aos seres humanos e por isso deve ser tutelada juridicamente.

Não por acaso, Rafael de Freitas Valle Dresch aponta que a teoria que melhor consubstancia a dignidade humana é a perspectiva das capacidades humanas, de Martha Nussbaum. É exatamente nessa esteira que se adota, como marco teórico, a teoria das capacidades centrais de Martha Nussbaum, como conteúdo apto a preencher a noção de dignidade humana. Segundo aquele autor, "a perspectiva das capacidades é a que melhor materializa a igual dignidade dos seres humanos e os direitos fundamentais que lhes consubstanciam". (DRESCH, 2013, p. 141).

Isso porque a teoria das capacidades, de Martha Nussbaum, concebe cada pessoa como um fim em si mesmo, preocupando-se com as oportunidades disponíveis para cada ser humano (NUSSBAUM, 2017, p. 38). Ora, “[...] o ser humano é dotado de proteção especial justamente pelo fato de não ser meio para os outros, mas fim em si mesmo" (LAMOUNIER, 2009, p. 138).

A teoria das capacidades é ainda comprometida com a liberdade, vale dizer, trata-se de "um enfoque comprometido com o respeito das faculdades de autodefinição das pessoas." (NUSSBAUM, 2017, p. 38, tradução nossa). ${ }^{6}$

A teoria das capacidades é pluralista quanto a valores (NUSSBAUM, 2017, p. 38), pois as capacidades são valoradas de forma diferente por cada ser humano, a depender de sua concepção de boa vida.

Nesse sentido, refere-se às capacidades, no plural, para o propósito explícito de “enfatizar que os elementos mais importantes da qualidade de vida das pessoas são plurais e qualitativamente distintos: a saúde, a integridade física, a educação e outros aspectos das

\footnotetext{
5 "Se las personas son consideradas en su calidad de ciudadanos y ciudadanas, todas ellas tienen iguales derechos." (NUSSBAUM, 2017, p. 51).

6 "Es, por lo tanto, un enfoque comprometido con el respeto a las facultades de autodefinición de las personas" (NUSSBAUM, p. 38).
} 
vidas individuais não podem ser reduzidas a uma única métrica sem distorção." (NUSSBAUM, 2017, p. 38, tradução nossa) ${ }^{7}$.

Por fim, a teoria das capacidades preocupa-se com as injustiças e desigualdades sociais, em especial daquelas que resultam em discriminação ou marginalização das pessoas, por falha ou omissão de capacidades. (NUSSBAUM, 2017, p. 38).

As capacidades são, portanto, enraizadas nas liberdades para agir ou atuar de cada pessoa (NUSSBAUM, 2017, p. 40). Segundo Martha Nussbaum, “[...] capacidade significa oportunidade de selecionar" (NUSSBAUM, 2017, p. 45, tradução nossa ${ }^{8}$ ), o que em muito se coaduna com as relações médico-pacientes e com a dignidade da mulher gestante.

Nessa perspectiva, "a dignidade da pessoa humana deve estabelecer a garantia das capacidades básicas para a sua realização como seres humanos” (DRESCH, 2013, p. 141). Conforme mencionado, as capacidades são individualizadas, sendo que cada ser as desenvolve de uma forma singular. Daí porque há a pluralidade de concepções de bem viver, que devem ser igualmente respeitadas (NUSSBAUM, 2017, p. 51). As capacidades, então, “devem ser garantidas através dos direitos fundamentais para fins de persecução da igual dignidade" (DRESCH, 2013, p. 144).

Portanto, a autora apresenta quais são as capacidades necessárias para que uma vida esteja à altura da dignidade humana. São capacidades chamadas capacidades centrais (NUSSBAUM, 2017, p. 53) as que viabilizam a vida digna, numa dinâmica de complementação de capacidades básicas e internas, combinando-as com habilidades de exercício efetivo. Portanto, segundo Martha Nussbaum, a uma vida digna perpassa pelas capacidades: 1- vida; 2- saúde física; 3- integridade física; 4- sentidos, imaginação e pensamentos; 5- emoções; 6- razão prática; 7- afiliação; 8- outras espécies; 9- jogo; e 10controle sobre o ambiente de alguém. (NUSSBAUM, 2017, p. 33- 34).

Dessa forma, a lista dessas capacidades revela-se próxima das noções doutrinárias e coerente com uma perspectiva de fundamentação intrassistêmica jurídico-normativa constitucional, uma vez que serve como instrumento de análise prática (DRESCH, 2013, 142), ao passo que "consubstancia os direitos fundamentais e a liberdade através das condições necessárias para a garantia de desenvolvimento de funcionalidades individuais

\footnotetext{
7 "enfatizar que los elementos más importantes de la calidad de vida de las personas son plurales y cualitativamente distintos: la salud, la integridad física, la educácion y otros aspectos de las vidas individuales no pueden ser reducidos a uma métrica única sin distorsionarse." (NUSSBAUM, p. 37-38).

8 “[...] capacidad significa oportunidad de selecionar."
} 
essenciais para assegurar oportunidades e liberdade" (DRESCH, 2013, 142). Vale dizer, se dignidade é um dos corolários do Direito Privado, fazendo-se presente por meio de vários dispositivos constitucionais, cabe destacar a igualdade formal entre homens e mulheres, sem distinção de qualquer natureza (BRASIL, 1988); o direito à integridade física (BRASIL, 1988, art. 5 XLIX); e o direito à saúde (BRASIL, 1988, art. 196) como premissas a sua efetiva e individualizada edificação. Dessa forma, as palavras de Rafael de Freitas Valle Dresch (2013) são esclarecedoras:

\begin{abstract}
O conteúdo da dignidade humana são os direitos e deveres humanos, garantidores das condições básicas para autorrealização plena dos seres humanos, que decorre do valor absoluto do indivíduo humano. Assim, há primazia da dignidade humana, sendo os direitos e deveres humanos aqueles que determinam as ações devidas e exigíveis em decorrência da dignidade humana. (DRESCH, 2013, p. 139).
\end{abstract}

Logo, tendo em vista que a indagação inicial versa sobre as características circunstanciais que formatam a episiotomia como ofensiva à dignidade da mulher parturiente, deve-se perpassar pelas capacidades centrais, na medida em que elas podem conferir substância à essa dignidade.

No tocante ao uso da episiotomia no momento do parto, frisa-se a possível violência a, pelo menos, três destas capacidades centrais, quais sejam, a saúde física, integridade física e afiliação. Na explicação de Martha Nussbaum, veja-se:

$[\ldots]$

2. Saúde física. Poder manter uma boa saúde, incluindo saúde reprodutiva; ser adequadamente nutrido; ter abrigo adequado.

3. Integridade física. Poder se mover livremente de um lugar para outro; estar seguro contra ataques violentos, incluindo agressão sexual e violência doméstica; ter oportunidades de satisfação sexual e de escolha em matéria de reprodução. $[\ldots]$

7. Afiliação.

A. Ser capaz de viver com e para com os outros, reconhecer e demonstrar preocupação com outros seres humanos, para se engajar em várias formas de interação social; ser capaz de imaginar a situação de outra. (Proteger essa capacidade significa proteger instituições que constituem e nutrem tais formas de afiliação, e também proteger a liberdade de reunião e discurso político).

B. Ter as bases sociais de auto-respeito e não-humilhação; ser capaz de ser tratado como um ser digno cujo valor é igual ao de outros. Isto implica disposições de não discriminação com base na raça, sexo, orientação sexual, etnia, casta, religião, nacionalidade. ${ }^{9}$ (NUSSBAUM, 2011, p. 33- 34, tradução nossa, grifo nosso).

\title{
${ }^{9}[\ldots]$
}

2. Bodily Health. Being able to have good health, including reproductive health; to be adequately nourished; to have adequate shelter. 
Dessa forma, inicialmente, percebe-se que a capacidade central "saúde física" é violada quando da feitura da episiotomia, sobretudo quando a mulher não é chamada a participar da definição do que pode ser por si considerado 'saúde'. Isso porque a saúde física é entendida um conceito dinâmico, que consiste no "domínio sobre o corpo que pode ser exercido na medida da sanidade mental da pessoa" (TEIXEIRA, 2010, p. 56). Dessa forma, a violação à saúde física estende prejuízo a outros campos para além do corpo, a saber, a saúde psíquica e mental.

Não é á toa que a saúde é entendida pela Organização Mundial da Saúde como tutela da integridade psíquica, física e social (TEIXEIRA, 2010, p. 52).

Por oportuno, a integridade física é entendida como:

\begin{abstract}
Um paradigma fixo, constante; na tutela da saúde, moldada pela autonomia, existe gradação da integridade física- a pessoa decide em qual medida esta se concretizaráalém de ter ou não vida, que nunca pode ser tomada como um dever, mas deve ser gozada como um direito. Devem ser considerados o discernimento, a competência e a possibilidade de autodeterminação dos indivíduos em relação à própria esfera corpórea, à própria vida e morte. É o pleno de poder de governar os próprios copo e a própria saúde. (TEIXIERA, 2010, p. 56).
\end{abstract}

Dessa forma, percebe-se que a capacidade central "integridade física" também é furtada das mulheres quando da adoção inopinada do procedimento da episiotomia. É, acima de tudo, nesses casos de alienação feminina do processo decisório pela episiotomia, uma violência exercida pelos/as obstetras de forma institucionalizada, atentatória à dignidade das mulheres, posto que é uma agressão contra a genitália feminina de forma injustificada. Em última análise, pode configurar-se como forma de agressão sexual contra a saúde reprodutiva

3. Bodily Integrity. Being able to move freely from place to place; to be secure against violent assault, including sexual assault and domestic violence; having opportunities fo $r$ sexual satisfaction and fo $r$ choice in matters of reproduction.

$[\ldots]$

7. Affiliation.

A. Being able to live with and toward others, to recognize and show concern fo $r$ other human beings, to engage in various forms of social interaction; to be able to imagine the situation o f another. (Protecting this capability means protecting institutions that constitute and nourish such forms o f affiliation, and also protecting the freedom of assembly and political speechB. Having the social bases of self-respect and non-humiliation; being able to be treated as a dignified being whose worth is equal to that of others. This entails provisions o f nondiscrimination on the basis o $\mathrm{f}$ race, sex, sexual orientation, ethnicity, caste, religion, national origin. (NUSSBAUM, 2011, p. 33- 34). 
das mulheres. É notório, portanto, que as integridades físicas das mulheres são colocadas em segundo plano, o que viola sua dignidade humana.

A capacidade central ligada à afiliação também pode ser mitigada com a episiotomia não consentida ou realizada em interesse diverso do da mulher. Explica-se. Ao valer-se da episiotomia, o profissional da saúde pode prejudicar, e muito, o período pós-parto da mulher, em favor de uma finalidade diversa que não o bem-estar da parturiente ou do recém-nascido. Vale frisar, trata-se de um dos procedimentos mais comuns na obstetrícia (FRIGO et al. 2014, p. 06), apesar dos prejuízos de ordem física e moral à parturiente. Dentre eles, relata-se que “as intervenções sofridas, tais como episiotomia, [...] dão início a uma história reprodutiva marcada por cicatrizes e perda da integridade do tecido perineal e uterino" (LEAL et al. 2014, p. 528).

Significa que, exatamente nesse tocante, a episiotomia pode refletir inefetivação da capacidade central "afiliação". Afinal, a mulher gestante deixa de ser lida como um fim em si mesma. É tratada em desigualdade em relação ao homem, o que implica em uma violência contra a dignidade da mulher, posto que não é tratada como digna de igual valor, sendo alvo de discriminação de gênero, o que pode ser somado a outros signos de opressão que a acometem no momento do atendimento médico-paciente. É a posição de mulher, ou seja, de sujeita a circunstância marcada pela questão de gênero, que a condiciona a tais práticas de subjugação da autonomia na definição da aplicação da episiotomia.

Dessa forma, entende-se que pelo menos três das dez capacidades centrais apresentadas por Martha Nussbaum podem ser diretamente violadas pelo procedimento inopinado da episiotomia. São elas: saúde física, integridade física e afiliação. Cumpre esclarecer que o rol de capacidades de Martha Nussbaum não é taxativo, podendo-se somar outras tantas capacidades que são eminentemente feridas em desrespeito à dignidade da mulher parturiente, que se encontra em situação de vulnerabilidade em dois campos: por ser mulher e por estar em período gravídico. A saúde, a integridade e a posição de mulher dessas parturientes devem ser devidamente tuteladas, diante da questão de gênero que determina a ofensa à dignidade.

Diante de todo o exposto, resta claro que a inopinada episiotomia de rotina pode ser tida como agressão à dignidade da mulher gestante, diante das consequências prejudiciais à sua saúde, integridade física e respeito mútuo (próprio de sua condição de pertencimento ao grupo). 
Parece necessária, portanto, para a efetivação da dignidade preenchida pelas capacidades centrais (individualmente densificadas), a concreção de mecanismos instrumentais que possam proteger as mulheres em situação gravídica de procedimentos arbitrários e prejudiciais para a saúde e dignidade.

\section{CONSIDERAÇÕES FINAIS}

O movimento feminista tem lutado, desde o século XIX, pelo fim da hierarquia de gênero e pela igualdade substancial entre homens e mulheres. Isso porque as mulheres são dignas de igual respeito e igual dignidade, devendo ser transpostas quaisquer manifestações de discriminação em razão de gênero. Dessa forma, procedimentos obstétricos que violam a integridade e a saúde da mulher, notadamente a episiotomia, devem ser questionados, com o desiderato de promover a tutela adequada da condição da mulher gestante em detrimento de possíveis abusos médicos.

O presente trabalho volta o olhar aos casos de aplicação da episiotomia nos quais não há recomendação médica ou autorização da mulher. Isso porque, conforme evidenciado, a episiotomia é realizada, em significativa parcela dos casos, sem anuência da parturiente ou sem comprovação científica de sua necessidade, podendo trazer prejuízos à saúde.

Ao lançar luzes aos procedimentos mencionados por meio da Teoria das Capacidades, percebe-se que algumas capacidades das mulheres podem ser tolhidas quando da feitura do procedimento obstétrico da episiotomia de rotina não consentida. São elas a saúde física, integridade física e afiliação, ou seja, três das dez capacidades centrais elencadas por Nussbaum (2017).

Por conseguinte, sendo a dignidade entendida como um status conferido a todas e todos pela condição de seres humanos, passível de densificação por meio das capacidades centrais elencadas por Martha Nussbaum (2017), percebe-se que a dignidade das mulheres gestantes fica mitigada diante da subtração de capacidades centrais quando da utilização injustificada e não autorizada do procedimento da episiotomia.

Dessa forma, às mulheres parturientes deve ser assegurada a proteção adequada de sua dignidade, expressada, no recorte do panorama descortinado pelo trabalho, pela integridade física, saúde e igual respeito. 
Conclui-se, portanto, que a dignidade humana, corolário do ordenamento jurídico brasileiro, tende a ser violada quando da realização de procedimentos não autorizados, desfundamentados cientificamente e pautados em interesses pragmáticos alheios à subjetividade da mulher parturiente, de modo a prejudicar sua saúde, integridade física e a condição de ser humano das mulheres.

\section{REFERÊNCIAS}

ASCENSÃO, José de Oliveira. O "fundamento do Direito": entre o Direito Natural e a Dignidade da Pessoa Humana. In: SÁ, Maria de Fátima Freire de; MOUREIRA, Diogo Luna; ALMEIDA, Renata Barbosa de (coord.). Direito Privado: revisitações. Belo Horizonte: Arraes Editores, 2013.

BENTO, Paulo Alexandre de Souza São; SANTOS, Rosângela da Silva. Realização da episiotomia nos dias atuais à luz da produção científica: uma revisão. Escola Anna Nery Revista de Enfermagem. Vol. 10 (3), p. 552-559, 2006. Disponível em: $<$ http://www.scielo.br/scielo.php?script=sci_arttext\&pid=S1414-81452006000300027>. Acesso em: 30 jun. 2019.

BRASIL. Constituição da República Federativa do Brasil de 1988. Diário Oficial da Uniãio, Brasília, 5 out. 1988. Disponível em:

<http://www.planalto.gov.br/ccivil_03/Constituicao/Constituicao.htm>. Acesso em: 29 jun. 2019.

BRASIL. Ministério da Saúde. Gabinete do Ministro. Portaria n ${ }^{\circ} 1.459$, de 24 de junho de 2011. Institui no âmbito do Sistema Único de Saúde - SUS - a Rede Cegonha. Diário Oficial da União, Poder Executivo, Brasília, DF, n. 121, 27 jun. 2011.

DRESCH, Rafael de Freitas Valle. Fundamentos do direito privado: uma teoria da justiça e da dignidade humana. São Paulo, Atlas, 2013.

FRIGO, Jucimar; CAGOL, Grasiele; ZOCCHE, Denise Azambuja; et al. Episiotomia: (des)conhecimento do procedimento sob a ótica da mulher. Brazilian Journal of Surgery and Clinical Research. Maringá, Master Editora, Vol. 6, n. 2, pp. 05-10, 2014. Disponível em: <https://www.mastereditora.com.br/periodico/20140403_200543.pdf>. Acesso em: 30 jun. 2019.

LAMOUNIER, João Maurício Pena. Interpretação do princípio da dignidade da pessoa humana. In: FIUZA, César; SÁ, Maria de Fátima Freire de; NAVES, Bruno Torquato de Oliveira. Direito Civil: atualidades III. Belo Horizonte: Del Rey, 2009.

LEAL, Maria do Carmo; PEREIRA, Ana Paula Esteves; DOMINGUES, Rosa Maria Soares Madeira; et al. Intervenções obstétricas durante o trabalho de parto e parto em mulheres brasileiras de risco habitual. Caderno Saúde Pública. Rio de Janeiro, 30 Sup. 517- 547, 
2014. Disponível em: <http://www.scielo.br/scielo.php?script=sci_arttext\&pid=S0102311X2014001300005>. Acesso em: 30 jun. 2019.

KAMPF, Cristiane; DIAS, Rafael de Brito. A episiotomia na visão da obstetrícia humanizada: reflexões a partir dos estudos sociais da ciência e tecnologia. Hist. cienc. saudeManguinhos, Rio de Janeiro, v. 25, n. 4, p. 1155-1160, Dec. 2018. Disponível em: <http://www.scielo.br/pdf/hcsm/v25n4/0104-5970-hcsm-25-04-1155.pdf>. Acesso em: 30 jun. de 2019.

NUSSBAUM, Martha Craven. Creating capabilities: the human development approach. Cambridge, Massachusetts, London: The Belknap Press of Harvard University Press, 2011.

NUSSBAUM, Martha C. Crear capacidades: propuesta para el desarrollo humano. Traducción de Albino Santos Mosquera. Barcelona, Espanha: Paidós es um sello editorial de Espasa Libros, 2017.

OLIVEIRA, Sonia Maria Junqueira V. de; MIQUILINI, Elaine Cristina. Frequência e critérios para indicar a episiotomia. Revista Escola de Enfermagem da USP. Vol. 39, p. 299- 295, 2005. Disponível em: <http://www.scielo.br/scielo.php?script=sci_arttext\&pid=S0080-62342005000300006>. Acesso em: 30 jun. 2019.

PITANGUI, Ana Carolina Rodarti; SOUSA, Lídia de; FERREIRA, Cristine Homsi Jorge; et al. Mensuração e características da dor perineal em primíparas submetidas à episiotomia. Acta Paulista de Enfermagem. Vol. 22, n. 1, p. 77-82, 2009. Disponível em: $<$ https://bdpi.usp.br/bitstream/handle/BDPI/7205/art_PITANGUI_Mensuracao_e_caracteristi cas_da_dor_perineal_em_2009.pdf?sequence=1 >. Acesso em: 30 jun. 2019.

PRADO, Daniela Siqueira et al. Practices and obstetric interventions in women from a state in the Northeast of Brazil. Rev. Assoc. Med. Bras., São Paulo , v. 63, n. 12, p. 10391048, Dec. 2017. Disponível em: <http://www.scielo.br/scielo.php?script=sci_arttext\&pid=S0104-42302017001201039>. Acesso em: 30 jun. de 2019.

SOUZA, Adriano Stanley Rocha Souza. O fundamento jurídico do dano moral: princípio da dignidade da pessoa humana ou punitive damages? In: FIUZA, César; SÁ, Maria de Fátima Freire de; NAVES, Bruno Torquato de Oliveira. Direito Civil: atualidades III. Belo Horizonte: Del Rey, 2009.

TEIXEIRA, Ana Carolina Brochado. Saúde, corpo e autonomia privada. Rio de Janeiro: Renovar, 2010.

TESSER, Charles Dalcanale; KNOBEL, Roxana; ANDREZZO, Halana Faria de Aguiar; et $a l$. Violência obstétrica e prevenção quaternária: o que é e o que fazer. Revista Brasileira de Medicina da Família e Comunidade. 2015, 10(35): 1-12. Disponível em: <https://www.rbmfc.org.br/rbmfc/article/view/1013>. Acesso em: 30 jun. 2019. 